\title{
Factor Structure and Psychometric Properties of the Danish Adaptation of the Instrument Quality in Psychiatric Care-Forensic In-Patient Staff (QPC-FIPS)
}

\author{
Lars-Olov Lundqvist'1,2,3* Erik Riiskjaer4, Kirsten Lorentzen" ${ }^{4}$, Agneta Schröder 3,5 \\ ${ }^{1}$ Centre for Rehabilitation Research, Örebro County Council, Örebro, Sweden \\ ${ }^{2}$ School of Law, Psychology and Social Work, Örebro University, Örebro, Sweden \\ ${ }^{3}$ School of Health and Medical Sciences, Örebro University, Örebro, Sweden \\ ${ }^{4}$ Public Health and Quality Improvement Centre, Central Denmark Region, Denmark \\ ${ }^{5}$ Psychiatric Research Centre, Örebro County Council, Örebro, Sweden \\ Email: ${ }^{*}$ lars-olov.lundqvist@orebroll.se
}

Received 2 October 2014; revised 1 November 2014; accepted 16 November 2014

Copyright (C) 2014 by authors and Scientific Research Publishing Inc.

This work is licensed under the Creative Commons Attribution International License (CC BY). http://creativecommons.org/licenses/by/4.0/

(c) (i) Open Access

\begin{abstract}
There is a need for an internationally standardized and psychometrically tested instrument to measure the perceptions of staff members on the quality of forensic inpatient care provided. The aim of the present study was to adapt the Swedish instrument Quality of Psychiatric Care-Forensic In-Patient Staff (QPC-FIPS) to the Danish context and to evaluate its psychometric properties and factor structure in this context. All permanently employed staff members at all 27 forensic inpatient wards in Denmark were invited to answer the Danish version of the QPC-FIPS. In total, 641 staff members participated, resulting in a response rate of $80 \%$. The Danish version of the $Q P C$ FIPS showed adequate psychometric properties and excellent goodness of fit of the hypothesised factor structure. Hence, the Danish QPC-FIPS is an excellent instrument for evaluating quality of forensic inpatient care both in clinical practice and in cross-cultural research. The members of staff generally reported that the care provided to patients was of high quality. The quality of the forensic-specific dimension was rated the highest, followed by the support, secluded environment, encounter, discharge and participation. The quality of the secure environment dimension was perceived to be the worst. The QPC-FIPS includes important aspects of staff members' assessments of quality of care and offers a simple and inexpensive way to evaluate psychiatric forensic inpatient care. The QPC-FIPS can be used together with the Quality of Psychiatric Care-Forensic In-Patient (QPC-FIP) instrument, which covers the same items and dimensions as the QPC-FIPS, to iden-
\end{abstract}

*Corresponding author.

How to cite this paper: Lundqvist, L.-O., Riiskjaer, E., Lorentzen, K. and Schröder, A. (2014) Factor Structure and Psychometric Properties of the Danish Adaptation of the Instrument Quality in Psychiatric Care-Forensic In-Patient Staff (QPC-FIPS). Open Journal of Nursing, 4, 878-885. http://dx.doi.org/10.4236/ojn.2014.412093 
tify patients' and staff members' views on quality of care and to improve the quality of forensic psychiatric care and benchmarking.

\author{
Keywords
}

\author{
Forensic Inpatient Care, Psychometric Properties, Denmark, Quality in Psychiatric Care-Forensic \\ In-Patient Staff (QPC-FIPS), Quality of Care
}

\title{
1. Introduction
}

In forensic psychiatry, as in all health care fields, the assessment of quality of care is becoming recognized as an important outcome measure of the care provided [1]. It is argued that health care should be effective and productive [2] and that it should ensure that patients receive care which is as safe and high quality as possible, regardless of policy changes that may affect the staff's ability to provide care [3]. Care providers have a responsibility to provide high quality care and should therefore make efforts to assess the quality of the care provided [4]. It is thus important that the care providers have information about how they perform and that they assess the quality of care they provide in relation to patients' perceptions of the care [5]. That information can then be used to improve care [1] as well as to support changes in the organization of care and in the staff's performance [6].

Although there is a growing interest in improving the quality of care in forensic psychiatric settings [7], staff members' assessments of quality of care are rarely used in the forensic psychiatric services [8] [9]. As a consequence, we know little about how staff members perceive the quality of care they provide. Recently, however, the instrument Quality in Psychiatric Care-Forensic In-Patient Staff (QPC-FIPS) questionnaire has been developed and shown to have adequate psychometric properties in the Swedish context [5]. Because there are no psychometrically evaluated instruments in forensic psychiatric care, there is potential for the QPC-FIPS to be used to assess the perceptions of the quality of care among forensic psychiatric care providers in other countries.

However, the use of an instrument in another cultural setting requires careful translation and adaptation to the specifics of the culture where it will be used [10] [11]. A cross-culturally validated instrument gives researchers not only an instrument with known properties to make systematic analyses [12], but also the opportunity to compare results across similar care environments from different countries in meaningful ways [13] or to perform benchmarking within [14] or across countries [7]. International comparisons will generate new and generalizable knowledge that can be used in quality of care improvement.

Previously, there has been no available instrument like the QPC-FIPS available in Danish. Therefore, the aim of the present study was to adapt the QPC-FIPS to the Danish context and to evaluate its psychometric properties and factor structure.

\section{Methods}

\subsection{Study Sample}

In Denmark, forensic psychiatric care is delivered through five regions. All permanently employed staff members at all 27 forensic inpatient wards in Denmark were invited to answer the Danish version of the QPC-FIPS. All major occupational groups were represented, including nurses, physicians, social and health care assistants, psychologists, social counselors and social workers. Staff members were informed that participation was voluntary and that their answers would remain anonymous.

In total, 641 members of staff completed the questionnaire, yielding a response rate of $80 \%$. Eleven participating staff members had $30 \%$ or more missing items on the questionnaire and were excluded from the analysis. Thus, the final study sample consisted of 630 members of staff, of whom 389 (61\%) were women and 248 (39\%) were men (four participants had missing values on gender). The members of staff were aged between 18 and 70 years, with a median age of 47 years.

\subsection{The Original Swedish QPC-FIPS Instrument}

The QPC-FIPS [5] is a self-reported, multi-dimensional instrument based on the Quality in Psychiatric CareForensic In-Patient (QPC-FIP) instrument developed by Schröder, Ågrim and Lundqvist [15] and adapted to 
measure perceptions among staff. The QPC-FIP was developed from a definition of quality of care based on a phenomenographic interview study with patients receiving both inpatient and outpatient care [16]. Both the QPC-FIP and the QPC-FIPS have been shown to have good psychometric properties [5] [15].

The QPC-FIPS measures quality of care using 34 items across seven dimensions: encounter, participation, discharge, support, secluded environment, secure environment and a forensic-specific dimension. Every item is related to the phrase "I experienced that..." All items are scored on 4-point Likert-type scales ranging from 1 (totally disagree) to 4 (totally agree). For all items, participants can respond with "not applicable". The questionnaire also includes a number of background questions concerning demographic characteristics and generally relevant clinical data. Finally, at the end of the questionnaire, there is an open-ended question for participants to offer further comments on the quality of care.

\subsection{Danish Adaption of the QPC-FIPS}

A forward-back translation process [17] was used for the translation of the original Swedish QPC-FIPS into Danish. A native Danish speaker and authorized translator with Swedish as a second language translated the Swedish version into Danish. Another independent authorized translator back-translated the Danish version into Swedish. Thereafter, the back-translation was discussed by the Swedish research group (LOL and AS). The Danish version was then compared with the Swedish version to identify any difficulties in the translation process and to scrutinize the convergence between the translation and back-translation. Some difficulties were found and were discussed with both translators. This led to some minor revisions of the translation. A preliminary version of the Danish QPC-FIPS was designed. The Swedish and Danish research groups subsequently discussed this version and compared it with the original QPC-FIPS to continue fitting the items into the forensic psychiatry context in Denmark.

The preliminary QPC-FIPS was validated with 20 employees from five different wards. The interviewed employees were social workers and social and health care assistants of both genders. The interviews were conducted as cognitive interviews lasting for around 30 minutes each. The interviewees were asked to answer the questionnaire while the interviewer observed to see whether certain questions caused trouble. Afterwards, the interviewer asked the employee to elaborate on the specific answers given and to explain what certain terms in the items meant to the employee. Any discrepancies between the theoretical meaning of the question and the employee's understanding of the question were noted. The Danish and the Swedish research groups reviewed the results from the validation, and some terms were altered to fit the Danish psychiatric context. The final instrument is available upon request from the first author.

\subsection{Data Analysis}

Imputation was performed before analysis by replacing missing data points with the item means. Descriptive statistics were produced using SPSS 21. Cronbach's alpha [18] was used to assess the scales, and the 0.70 criterion was used to determine adequate homogeneity [19]. To test the factor structure of the QPC-FIPS, confirmatory factor analysis (CFA) was performed using LISREL 8.8 [20]. Generalized weighted least squares estimation was used on the asymptotic covariance matrices. The PRELIS program [21] obtained the polychoric and polyserial correlation matrix. As recommended by Jöreskog and Sörbom [20], for ordinal measurement variables, the parameters were estimated by the weighted least squares method using the asymptotic covariance matrix.

To test the tenability of the factor structure model proposed a priori and based on the original Swedish QPCFIPS [5], a CFA was performed, specified with the following model: Items 7, 10, 11, 12, 15, 17, 19 and 24 were assumed to represent encounter; items 1, 5, 6, 13, 14, 25, 27 and 28 to represent participation; items 8,16 and 20 to represent discharge; items $18,21,22$ and 23 to represent support; items 3 and 26 to represent secluded environment; items 2, 4 and 9 to represent secure environment and items 29 through 34 to represent forensic unitspecific situations.

The Satorra-Bentler scaled chi-squared ( $\left.\mathrm{SB} \chi^{2}\right)$ test, the comparative fit index (CFI), the standardized root mean square residual (SRMR) and the root mean square of approximation (RMSEA) were used to evaluate the adequacy of the models. Values $\geq 0.90$ and 0.95 for the CFI, $\leq 0.10$ and 0.08 for the SRMR, and $<0.08$ and 0.05 for the RMSEA were considered to constitute adequate and excellent levels of goodness of fit, respectively [22][24]. 


\section{Results}

\subsection{Psychometric Evaluation of the QPC-FIPS}

The CFA based on the Swedish QPC-FIPS factor structure showed a significant chi square (SB $\chi^{2}=1258.12$, $\mathrm{df}$ $=506, \mathrm{p}<0.001)$, a CFI of 0.99, an RMSEA of $0.048(\mathrm{CI}=0.045-0.052)$, a $\mathrm{p}$-value of .81 for the test of close fit based on the RMSEA (RMSEA < 0.05), and an SRMR of 0.078. Taken together, these results indicate an excellent goodness of fit. Summary statistics are given in Table 1. As seen in Table 2, four (19\%) of the correlation coefficients among the QPC-FIPS dimensions were strong $(>0.60)$ and $12(57 \%)$ coefficients were moderate (0.40 - 0.60) in size, implying the possibility of a common second-order factor. A test of a common second-order factor showed, however, a worse fit $\left(\mathrm{SB} \chi^{2}=2268.07, \mathrm{df}=527\right)$, so this model was discarded. Therefore, the model specified a priori with seven first-order factors with 34 items was regarded as a satisfactory representation of the factor structure of the Danish version of the QPC-FIPS and was considered the final model.

\subsection{Descriptions of Staff Members' Views of Quality of Forensic Inpatient Care}

Means and standard deviations of the seven QPC-FIPS dimensions and associated items are given in Table 1. Overall, the staff perceived the quality of the forensic-specific dimension as the highest, followed by the quality of the support dimension, which was somewhat lower. The next highest scores were assigned for quality on the secluded environment, encounter, discharge and participation dimensions. The quality of the secure environment dimension was perceived as the worst. As seen in Figure 1, and supported by Bonferroni corrected t-tests, the perceived quality of the forensic-specific dimension was not significantly different from the second-ranked dimension of support. The perceived quality of the support dimension was significantly greater than that of the secluded environment $\left(\mathrm{t}_{(629)}=4.70, \mathrm{p}<0.0001\right)$, which was, in turn, significantly greater than that of encounter $\left(\mathrm{t}_{(629)}=4.19, \mathrm{p}<0.0001\right)$. Perceptions of quality did not differ between the encounter and discharge dimensions. The perceived quality of discharge was significantly greater than that of the participation dimension $\left(\mathrm{t}_{(629)}=\right.$ $12.41, \mathrm{p}<0.0001$ ), and the perceived quality of participation was significantly greater than that of the lowest ranked dimension, secure environment $\left(\mathrm{t}_{(629)}=12.57, \mathrm{p}<0.0001\right)$.

\section{Discussion}

The present study showed that the factor structure of the Danish version of the QPC-FIPS was equivalent to that proposed on the basis of the original Swedish version [5], demonstrating that the concept of quality of forensic psychiatric care held by staff in Denmark are in keeping with the concept held by staff in Sweden. Factor loadings as well as homogeneity of the dimensions were also in keeping with the Swedish version. Hence, this study has shown that the methods used to adapt and standardize the Swedish QPC-FIPS instrument for applicability in the Danish context were successful.

The Danish version of the QPC-FIPS is the first instrument for measuring staff members' perceptions of quality of care in forensic inpatient care settings in Denmark. The instrument was rigorously translated and adapted to the Danish culture. Most of the adaptation of the instrument was related to semantic equivalence. The selection of the method of interviews was time consuming but very important for the adaptation.

The staff members reported generally high quality of care (i.e., a mean scores over 2.5 , which is the centre of the scale). The highest perceptions of quality of care were found in the forensic-specific dimension, and the lowest perceptions were found in the secure environment dimension. The low ratings in the secure environment dimension are in line with previous findings among forensic inpatient staff in Sweden [5]. This finding may indicate that the staff, relatively speaking, did not perceive the ward environment as safe for the patients. This is somewhat puzzling because, as patients have been sentenced for a crime, the focus of forensic psychiatry is on safety [25], and the staff should provide a secure base for patients in the ward [26]. This is in line with interviews among staff, where they expressed the view that patients should feel safe and secure and not have to be disturbed by fellow patients in the ward [16]. Our findings, however, may indicate that, relative to other quality of care dimensions, security is an area for improvement. Notably, the lowest QPC-FIPS rating was on the item "the patients are not disturbed by fellow patients".

The present study has several strengths, such as the thorough translation and adaptation process, the inclusion of all wards in Denmark, the ease of use and administration of the questionnaire, the high response rate and the low frequency of missing items, there are some limitations. For instance, it should be noted that Denmark and 
Table 1. Summary statistics of confirmatory factor analysis of the QPC-FIPS (N=630).

\begin{tabular}{|c|c|c|c|c|}
\hline QPC-FIPS Items and Dimensions & Loading & $\alpha$ & M & SD \\
\hline Total QPC-FIPS (34 Items) & & 0.93 & 3.22 & 0.43 \\
\hline 1. Encounter (8 items) & & 0.89 & 3.27 & 0.53 \\
\hline 07. Gives support when the patients need it & 0.40 & & 3.27 & 0.73 \\
\hline 10. Committed staff & 0.53 & & 2.88 & 0.79 \\
\hline 11. Shows empathy & 0.54 & & 3.26 & 0.72 \\
\hline 12. Cares if the patients get angry & 0.79 & & 3.44 & 0.71 \\
\hline 15. Respects the patients & 0.47 & & 3.34 & 0.70 \\
\hline 17. Shows understanding & 0.63 & & 3.24 & 0.71 \\
\hline 19. Has time to listen & 0.42 & & 3.15 & 0.73 \\
\hline 24. Cares about the patients' care & 0.65 & & 3.56 & 0.63 \\
\hline 2. Participation (8 items) & & 0.84 & 2.95 & 0.56 \\
\hline 01. Patients have influence over their care & 0.45 & & 2.84 & 0.82 \\
\hline 05. Patients' views of the right care are respected & 0.38 & & 2.54 & 0.82 \\
\hline 06. Patients take part in decision making about their care & 0.46 & & 2.79 & 0.84 \\
\hline 13. Benefit is drawn from the patients' earlier experiences of treatment & 0.54 & & 3.19 & 0.78 \\
\hline 14. Patients help to recognize signs of deterioration & 0.61 & & 2.98 & 0.91 \\
\hline 25. Patients are informed in a way that they understand & 0.50 & & 3.25 & 0.73 \\
\hline 27. Patients have knowledge about their mental troubles & 0.56 & & 3.15 & 0.77 \\
\hline 28. Patients receive information about treatment alternatives & 0.62 & & 2.82 & 0.96 \\
\hline 3. Discharge (3 items) & & 0.58 & 3.26 & 0.72 \\
\hline 08. Planning of the patients' continued treatment & 0.46 & & 2.95 & 0.78 \\
\hline 16. Patients are offered follow-up after discharge & 0.57 & & 3.29 & 1.19 \\
\hline 20. Patients know where to turn & 0.59 & & 3.52 & 0.94 \\
\hline 4. Support (4 items) & & 0.76 & 3.53 & 0.53 \\
\hline 18. Stops the patients from hurting others & 0.67 & & 3.54 & 0.65 \\
\hline 21. Stops the patients from hurting themselves & 0.83 & & 3.66 & 0.58 \\
\hline 22. Nothing shameful about having mental troubles & 0.80 & & 3.46 & 0.73 \\
\hline 23. Shame and guilt must not get in the way & 0.84 & & 3.45 & 0.80 \\
\hline 5. Secluded environment ( 2 items) & & 0.65 & 3.39 & 0.75 \\
\hline 03. Access to a secluded place & 1.11 & & 3.43 & 0.82 \\
\hline 26. There is a secluded place & 1.01 & & 3.35 & 0.92 \\
\hline 6. Secure environment (3 items) & & 0.61 & 2.62 & 0.62 \\
\hline 02. High level of security in the ward & 0.51 & & 3.03 & 0.88 \\
\hline 04. Feels secure with fellow patients & 0.67 & & 2.74 & 0.79 \\
\hline 09. Not disturbed by fellow patients & 0.56 & & 2.10 & 0.80 \\
\hline 7. Forensic specific (6 items) & & 0.69 & 3.54 & 0.41 \\
\hline 29. Informed of their rights & 0.73 & & 3.84 & 0.45 \\
\hline 30. Help the patients contact the Administrative Court & 0.87 & & 3.86 & 0.41 \\
\hline 31. The doctor explains... & 0.55 & & 3.37 & 0.76 \\
\hline 32. Support from their lawyer & 0.31 & & 3.40 & 0.84 \\
\hline 33. Staffs help the patients with processing their crime & 0.52 & & 3.22 & 0.79 \\
\hline 34. Staffs are involved in the patients' care... & 0.48 & & 3.56 & 0.66 \\
\hline
\end{tabular}

Notes: QPC-FIPS = Quality of Psychiatric Care-Forensic In-Patient Staff; $\alpha=$ Chronbach alpha. 
Table 2. Correlation coefficients of QPC-FIPS dimensions $(\mathrm{N}=630)$.

\begin{tabular}{lcccccccc}
\hline & QPC-FIPS Dimension & 1 & 2 & 3 & 4 & 5 & 6 & 7 \\
\hline 1 & Encounter & 1.00 & & & & & & \\
2 & Participation & 0.67 & 1.00 & & & & & \\
3 & Discharge & 0.46 & 0.55 & 1.00 & & & & \\
4 & Support & 0.66 & 0.57 & 0.47 & 1.00 & & & \\
5 & Secluded environment & 0.41 & 0.38 & 0.34 & 0.40 & 1.00 & & \\
6 & Secure environment & 0.44 & 0.42 & 0.32 & 0.37 & 0.43 & 1.00 & 0.32 \\
7 & Forensic-specific & 0.61 & 0.59 & 0.47 & 0.61 & 0.40 & 1.00 \\
\hline
\end{tabular}

Notes: All correlation coefficients are significant at $\mathrm{p}<0.001$.

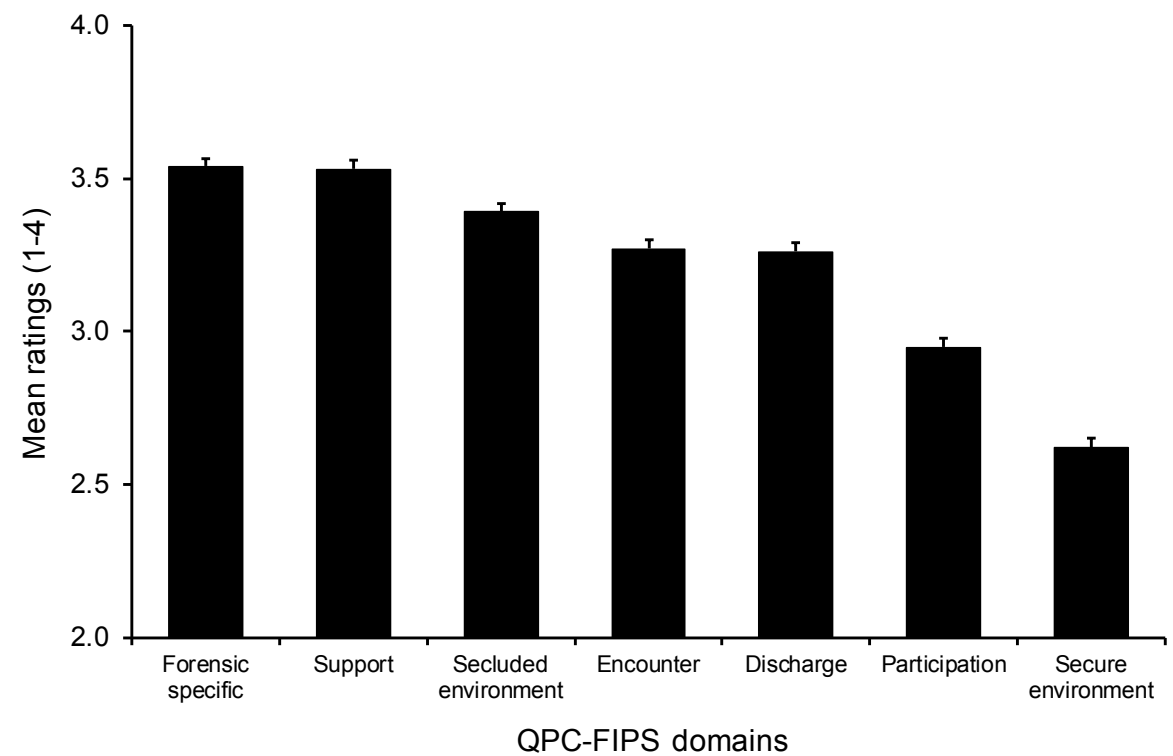

Figure 1. Mean ratings of the Danish QPC-FIPS dimensions. Error bars represent one Standard Error of the Mean.

Sweden are culturally similar. However, as a first step to test the cross-cultural validity of the QPC-FIPS, the adaptation to Danish was deemed suitable. To permit international comparison, adaptation and standardization of the QPC-FIPS instrument into languages and countries outside Scandinavia is warranted [27]. To improve the quality of care further, both patients' and staff members' views of quality of care should be considered [28]. The planned development of the QPC for the forensic psychiatric area should include both the patients' and the staff members' perspectives.

\section{Conclusion}

The result of this study demonstrates that the Danish QPC-FIPS has good psychometric properties, which is an excellent instrument to measure the staff members' perceptions of psychiatric inpatient care and has the potential to be useful in cross-cultural research.

\section{Clinical Implications}

The QPC-FIPS is inexpensive and easy to use. It can be used together with the Danish-adapted and psychometrically tested instrument for patients, the Quality in Psychiatric Care-Forensic In-Patient questionnaire [29], to identify both patients' and staff members' views on quality of care to improve the quality of forensic psychiatric care and benchmarking. 


\section{Acknowledgements}

For administrative support for this study we thank Gitte Dahl, Public Health and Quality Improvement Centre, Central Denmark Region, Denmark, and Anna Wadefjord, Psychiatric Research Centre, Örebro County Council, Örebro, Sweden.

\section{References}

[1] Mainz, J., Krog Randrup, B., Bjørnshave, B. and Bartels, P. (2004) Nationwide Continuous Quality Improvement Using Clinical Indicators: The Danish National Indicator Project. International Journal for Quality in Health Care, 16, 45-50. http://dx.doi.org/10.1093/intqhe/mzh031

[2] Petterson, I.-L. and Arnetz, B.B. (1997) Measuring Psychosocial Work Quality and Health: Development of Health Care Measures of Measurement. Journal of Occupational Health Psychology, 2, 229-241. http://dx.doi.org/10.1037/1076-8998.2.3.229

[3] Blendon, R.J., Schoen, C., Donelan, K., Osborn, R., DesRoches, C.M., Scoles, K., Davis, K., Binns, K. and Zapert, K. (2001) Physicians' Views on Quality of Care: A Five-Country Comparison. Health Affairs, 20, 233-243. http://dx.doi.org/10.1377/hlthaff.20.3.233

[4] World Health Organization (2006) Quality of Care: A Process for Making Strategic Choices in Health Systems. WHO Press, Geneva.

[5] Schröder, A. and Lundqvist, L.-O. (2013) The Quality in Psychiatric Care-Forensic In-Patient Staff (QPC-FIPS) Instrument: Psychometric Properties and Staff Views of the Quality of Forensic Psychiatric Services in Sweden. Open Journal of Nursing, 3, 330-341. http://dx.doi.org/10.4236/ojn.2013.33045

[6] Jung, H., Wensing, M. and Grol, R. (1997) What Makes a Good General Practitioner: Do Patients and Doctors Have Different Views? British Journal of General Practice, 47, 805-809.

[7] Hussey, P.S., Anderson, G.F., Osborn, R., Feek, C., McLaughlin, V., Millar, J. and Epstein, A. (2004) How Does the Quality of Care Compare in Five Countries? Health Affairs, 23, 89-99. http://dx.doi.org/10.1377/hlthaff.23.3.89

[8] DeMarco, R., Flaherty, L., Glod, C., Merril, N., Terk, K. and Plasse, M. (2004) Staff and Client Perceptions of Unit Quality: A Pilot Study. Journal of Psychosocial Nursing and Mental Health Service, 42, 36-43.

[9] Valenstein, M., Mitchinson, A., Ronis, D.L., Alexander, J.A., Duffy, S.A., Craig, T.J. and Lawton Barry, K. (2004) Quality Indicators and Monitoring of Mental Health Services: What Do Frontline Providers Think? American Journal of Psychiatry, 161, 146-153. http://dx.doi.org/10.1176/appi.ajp.161.1.146

[10] Cramer, J.A., Perrine, K., Devinsky, O., Bryant-Comstock, L., Meador, K. and Hermann, B. (1998) Development and Cross-Cultural Translations of a 31-Item Quality of Life in Epilepsy Inventory. Epilepsia, 39, 81-88. http://dx.doi.org/10.1111/j.1528-1157.1998.tb01278.x

[11] Henderson, C., Hales, H. and Ruggeri, M. (2003) Cross-Cultural Differences in the Conceptualisation of Patients' Satisfaction with Psychiatric Services - Content Validity of the English Version of the Verona Service Satisfaction Scale. Social Psychiatry Psychiatric Epidemiology, 38, 142-148. http://dx.doi.org/10.1007/s00127-003-0606-7

[12] Ogloff, J.R.P., Roesch, R. and Eaves, D. (2000) International Perspective on Forensic Mental Health Systems. International Journal of Law \& Psychiatry, 23, 429-431. http://dx.doi.org/10.1016/S0160-2527(00)00062-5

[13] Sartorius, N. and Helmchen, H. (1981) Aims and Implementation of Multi-Centre Studies. Modern Problems of Pharmacopsychiatry, 16, 1-8.

[14] Mainz, J., Hjulsager, M., Eriksen, M.T. and Burgaard, J. (2009) National Benchmarking between the Nordic Countries on the Quality of Care. Journal of Surgical Oncology, 99, 505-507. http://dx.doi.org/10.1002/jso.21204

[15] Schröder, A., Ågrim, J. and Lundqvist, L.-O. (2013) The Quality in Psychiatric Care-Forensic In-Patient Instrument: Psychometric Properties and Patient Views of the Quality of Forensic Psychiatric Services in Sweden. Journal of Forensic Nursing, 9, 225-234. http://dx.doi.org/10.1097/JFN.0b013e31827f5d2f

[16] Schröder, A. and Ahlström, G. (2004) Psychiatric Care Staff's and Care Associates' Perceptions of the Concept of Quality of Care: A Qualitative Interview Study. Scandinavian Journal of Caring Sciences, 18, 204-212. http://dx.doi.org/10.1111/j.1471-6712.2004.00271.x

[17] Wild, D., Grove, A., Martin, M., Eremenco, S., McElroy, S., Verjee-Lorenz, A. and Erikson, P. (2005) Principles of Good Practice for the Translation and Cultural Adaptation Process for Patient-reported Outcomes (PRO) Measures: Report of the ISPOR Task Force for Translation and Cultural Adaptation. Value in Health, 8, 94-104. http://dx.doi.org/10.1111/j.1524-4733.2005.04054.x

[18] Cronbach, L.J. (1951) Coefficient Alpha and the Internal Structure of Tests. Psychometrika, 16, 297-334. http://dx.doi.org/10.1007/BF02310555 
[19] Nunnally, J. and Bernstein, I. (1994) Psychometric Theory. 3rd Edition, McGraw-Hill, New York.

[20] Jöreskog, K.G. and Sörbom, D. (1996) LISREL 8: User's Reference Guide. 2nd Edition, Scientific Software International, Chicago.

[21] Jöreskog, K.G. and Sörbom, D. (1988) PRELIS-A Program for Multivariate Data Screening \& Data Summarization, a Preprocessor for LISREL. 2nd Edition, Scientific Software Inc., Chicago.

[22] Bentler, P.M. (1990) Comparative Fit Indexes in Structural Models. Psychological Bulletin, 107, 238-246. http://dx.doi.org/10.1037/0033-2909.107.2.238

[23] Browne, M.W. and Cudeck, R. (1993) Alternative Ways of Assessing Model Fit. In: Bollen, K.A. and Long, J.S., Eds., Testing Structural Equation Models, Sage Publications, Newbury Park, 136-162.

[24] Vandenberg, R.J. and Lance, C.E. (2000) A Review and Synthesis of the Measurement Invariance Literature: Suggestions, Practices, and Recommendations for Organizational Research. Organizational Research Methods, 3, 4-70. http://dx.doi.org/10.1177/109442810031002

[25] Kumpula, E. and Ekstrand, P. (2013) "Doing Things Together": Male Caregivers' Experiences of Giving Care to Patients in Forensic Psychiatric Care. Journal of Psychiatric \& Mental Health Nursing, 20, 64-70. http://dx.doi.org/10.1111/j.1365-2850.2012.01887.x

[26] Adshead, G. (1998) Psychiatric Staff as Attachment Figures. Understanding Management Problems in Psychiatric Services in the Light of Attachment Theory. The British Journal of Psychiatry, 172, 64-69. http://dx.doi.org/10.1192/bjp.172.1.64

[27] Hofstede, G. (1983) The Cultural Relativity of Organizational Practices and Theories. Journal of International Business Studies, 14, 75-89.

[28] Haas, J.S., Cook, E.F., Puopolo, A.L., Burstin, H.R., Cleary, P.D. and Brennan, T.A. (2000) Is the Professional Satisfaction of General Internists Associated with Patient Satisfaction? Journal of General Internal Medicine, 15, 122-128. http://dx.doi.org/10.1046/j.1525-1497.2000.02219.x

[29] Lundqvist, L.-O., Lorentzen, K., Riiskjaer, E. and Schröder, A. (2014) A Danish Adaptation of the Quality in Psychiatric Care-Forensic In-Patient Questionnaire: Psychometric Properties and Factor Structure. Journal of Forensic Nursing, 10, 168-174. http://dx.doi.org/10.1097/JFN.0000000000000036 
Scientific Research Publishing (SCIRP) is one of the largest Open Access journal publishers. It is currently publishing more than 200 open access, online, peer-reviewed journals covering a wide range of academic disciplines. SCIRP serves the worldwide academic communities and contributes to the progress and application of science with its publication.

Other selected journals from SCIRP are listed as below. Submit your manuscript to us via either submit@scirp.org or Online Submission Portal.
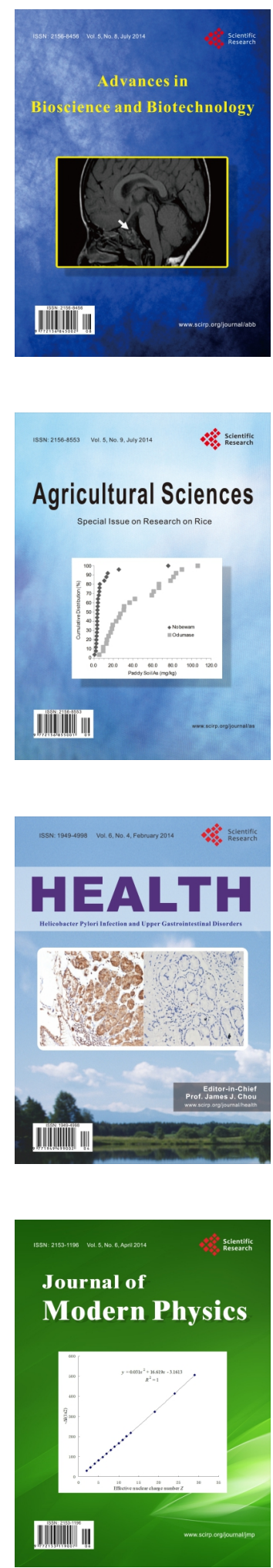
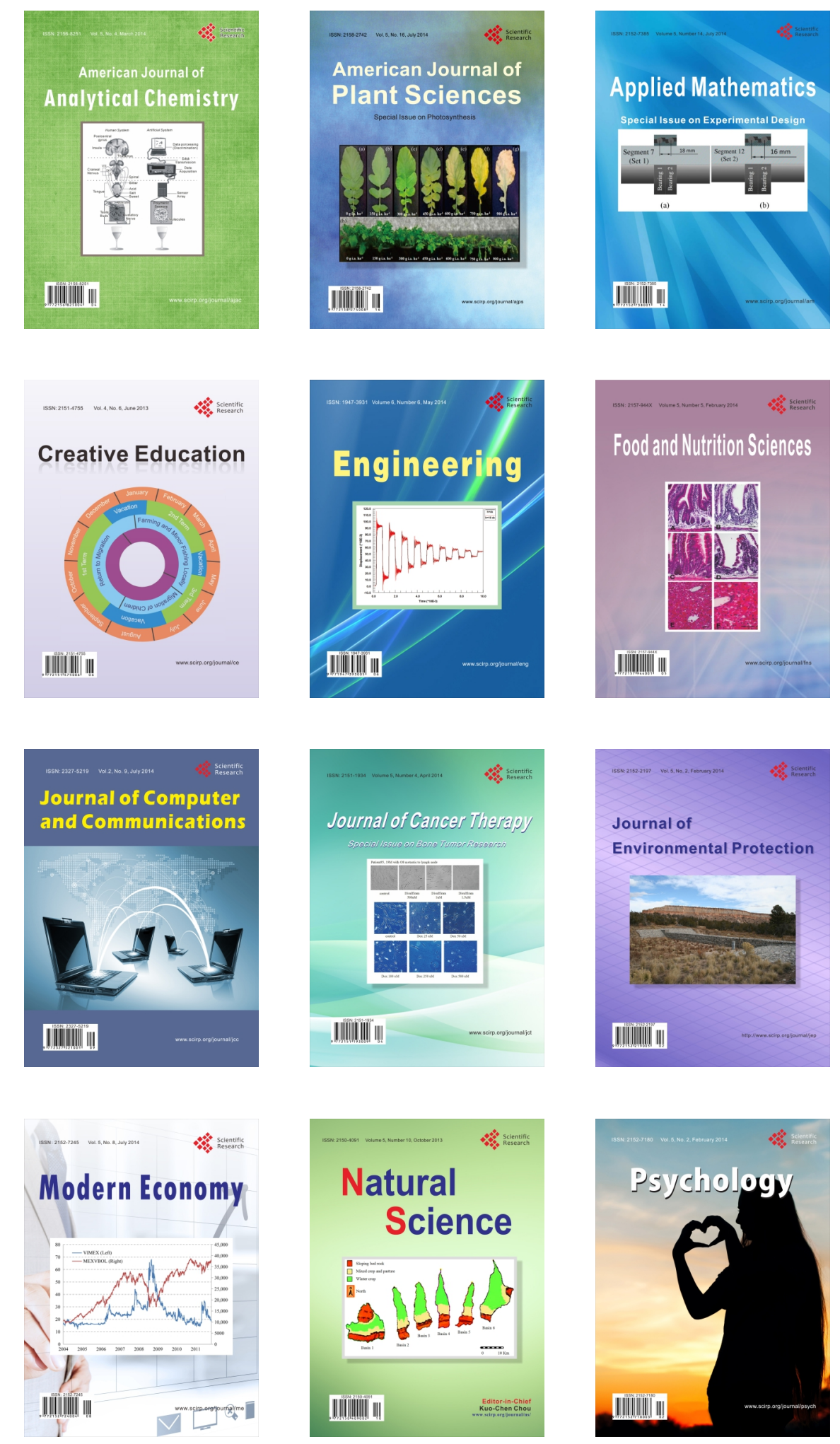